\title{
Assessment of Cosmic Background Attenuation at Building 3425 (Underground Laboratory)
}

\author{
RT Kouzes \\ JD Borgardt \\ AT Lintereur \\ ME Panisko
}

October 5, 2009

\section{Pacific Northwest}

NATIONAL LABORATORY

Proudly Operated by Battelle Since 1965 


\title{
DISCLAIMER
}

This report was prepared as an account of work sponsored by an agency of the United States Government. Neither the United States Government nor any agency thereof, nor Battelle Memorial Institute, nor any of their employees, makes any warranty, express or implied, or assumes any legal liability or responsibility for the accuracy, completeness, or usefulness of any information, apparatus, product, or process disclosed, or represents that its use would not infringe privately owned rights. Reference herein to any specific commercial product, process, or service by trade name, trademark, manufacturer, or otherwise does not necessarily constitute or imply its endorsement, recommendation, or favoring by the United States Government or any agency thereof, or Battelle Memorial Institute. The views and opinions of authors expressed herein do not necessarily state or reflect those of the United States Government or any agency thereof.

\author{
PACIFIC NORTHWEST NATIONAL LABORATORY \\ operated by \\ BATTELLE \\ for the \\ UNITED STATES DEPARTMENT OF ENERGY \\ under Contract DE-AC05-76RL01830
}

Printed in the United States of America
Available to DOE and DOE contractors from the Office of Scientific and Technical Information,
P.O. Box 62, Oak Ridge, TN 37831-0062;
ph: (865) 576-8401
fax: $(865)$ 576-5728
email: reports@adonis.osti.gov

\begin{abstract}
Available to the public from the National Technical Information Service, U.S. Department of Commerce, 5285 Port Royal Rd., Springfield, VA 22161 ph: (800) 553-6847 fax: $(703) 605-6900$ email: orders@ntis.fedworld.gov online ordering: http://www.ntis.gov/ordering.htm
\end{abstract}

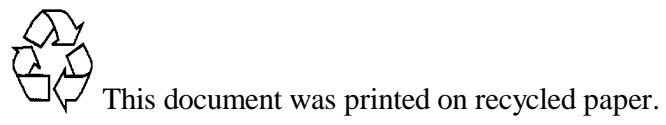




\section{Assessment of Cosmic Background Attenuation at Building 3425 (Underground Laboratory)}

RT Kouzes

JD Borgardt

AT Lintereur

ME Panisko

October 5, 2009

Pacific Northwest National Laboratory

Richland, Washington 99352 


\section{Executive Summary}

Specifications for the Underground Facility (Building 3425) in the Radiation Detection and Nuclear Sciences complex presently under construction at Pacific Northwest National Laboratory mandate a 30 meters water equivalent shielding for cosmic background attenuation at the 30-foot $(9.1-\mathrm{m})$ underground depth of the laboratory. A set thickness of a specified fill material was determined; however a thinner layer of a higher density material was used for the earthen bunker. Questions arose as to whether this altered configuration met the required shielding specifications. A series of measurements with a 4"x4"x16" NaI(Tl) detector (Scionix Holland, 3.5N-E2-X) were made to address this concern . Data were obtained at the surface and several locations within the underground facility in order to obtain an experimental value for the attenuation of cosmic radiation. This experimental result was compared with the contracted attenuation.

The result of the measurement indicates that the maximum depth of the underground facility (Building 3425 ) is $\mathbf{3 5}$ meters water equivalent. However, this is a maximum effective depth, since the measured surface flux has contributions to the spectrum from sources other than muons, resulting in an increase in the measured counts on the surface and an overestimate of the equivalent depth. This is because most surface contributions other than muons are easily stopped within a short penetration of the soil. 


\section{Contents}

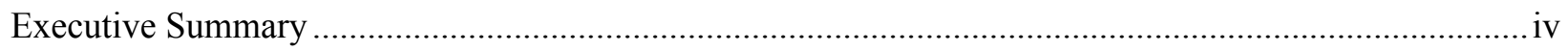

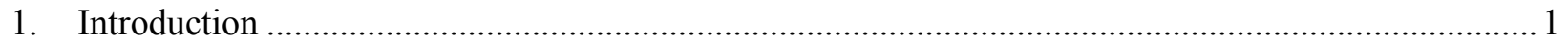

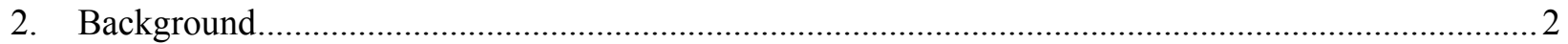

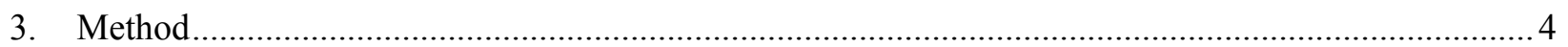

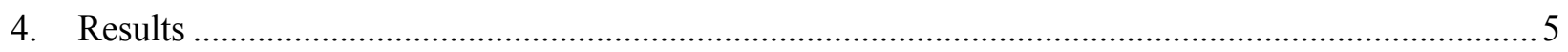

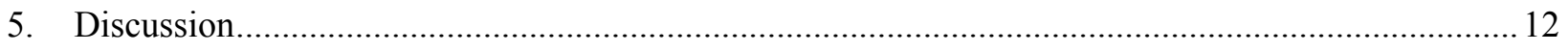

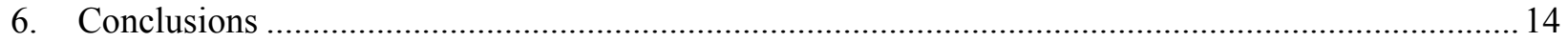

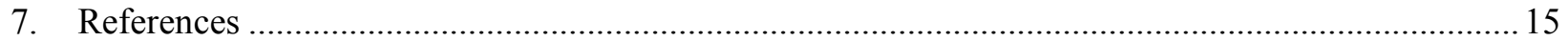




\section{Figures and Tables}

\section{Figures}

Figure 1. Variation of the specific energy loss in air versus energy of the charged particles shown. (From

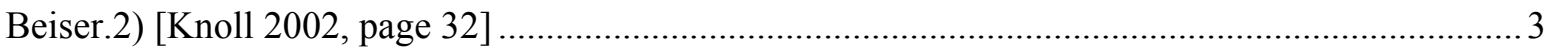

Figure 2. a) view of earthen bunker from NE; b) view of earthen bunker from SE ............................... 4

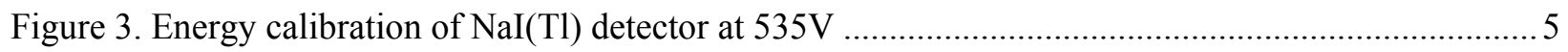

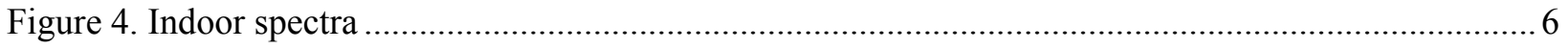

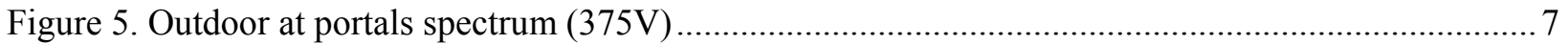

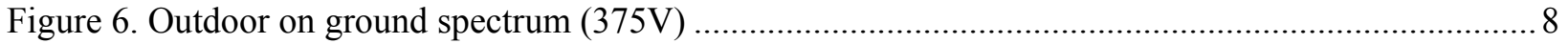

Figure 7. a) Underground spectrum in shaft (375 V); b) Magnified underground spectrum in shaft (375 V)

Figure 8. a) Underground spectrum near west wall (375 V); b) Magnified spectrum near west wall (375

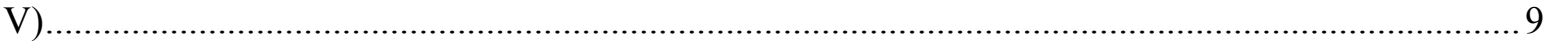

Figure 9. a) Underground spectrum center of room (375 V); b) Magnified spectrum center of room (375

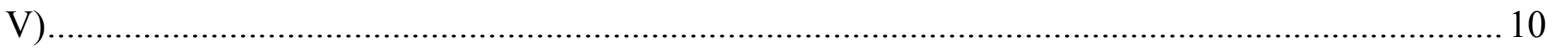

Figure 10. a) Underground spectrum near east wall (375 V); b) Magnified spectrum near east wall (375 $\mathrm{V})$

\section{Tables}

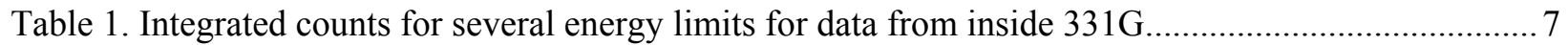

Table 2. Integrated counts for several energy limits outside 331G.................................................. 7

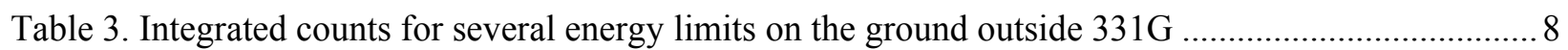

Table 4. Integrated counts for several energy limits in the shaft at the underground laboratory................ 9

Table 5. Integrated counts for several energy limits made near the west wall. ...................................... 10

Table 6. Integrated counts for several energy limits in the middle of the underground laboratory............ 10

Table 7. Integrated counts for several energy limits at the east end of the underground laboratory.......... 11

Table 8. Summary of counts for each location for energies of $\sim 40-90 \mathrm{MeV}$ (Channels 450-1023).......... 12

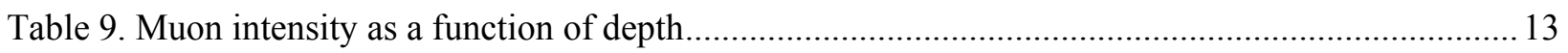




\section{Introduction}

Contracted specifications for the underground facility at Building 3425, a 30-foot (9.1-m) depth underground facility that is part of the Radiation Detection and Nuclear Sciences complex presently under construction at Pacific Northwest National Laboratory, require an attenuation of cosmic background equivalent to 30 meters water equivalent. A specific thickness of a specific density fill was selected to make the earthen bunker, whose function is to provide additional surface shielding for this facility. A thinner layer of a higher density material than soil was used to meet the specification.

This report details cosmic ray measurements made in August 2009 to test this assertion. The concept was to measure the muon flux above ground and below ground at three locations in the 3425 facility and from this determine the attenuation factor. 


\section{Background}

Cosmic rays are energetic particles of extra-terrestrial origin that enter the Earth's atmosphere. The primary cosmic radiation is made up of charged particles, predominantly protons, plus some heavy ions that have energy spectra extending into the $\mathrm{GeV}$ range and beyond. Cosmic sources can vary with the solar cycle and are influenced by latitude, barometric pressure, solar activity, diurnal cycle, and weather [Keller 2009]. This primary cosmic radiation interacts with the atmosphere, generating a shower of very high-energy secondary particles, including electrons, protons, neutrons, photons, and unstable mesons that quickly decay into muons. Muons minimally interact with the atmosphere, which, with the relativistic time dilation effect, allow them to reach the surface of the Earth. The muon flux for momenta $\geq 350 \mathrm{MeV} / \mathrm{c}$ at sea level is about $170 /\left(\mathrm{m}^{2} \cdot \mathrm{sec}\right)$ [Grieder 2001, pg 354]. At the Earth's surface this secondary cosmic radiation is narrowly collimated along the line of the original radiation. Fast neutrons from cosmic interactions can also create additional gamma rays.

The specific energy loss for many charged particles decreases exponentially, reaching an approximately constant asymptotic value of $2 \mathrm{MeV} /\left(\mathrm{g} / \mathrm{cm}^{2}\right)$ in light materials at cosmic energies above several hundred $\mathrm{MeV}$ [Knoll 2002, page 32]. Beyond this incident cosmic ray energy threshold these "minimally ionizing particles" lose a set amount of energy in a given thickness of a specified material (Figure 1).

For a 4"x4"x16" $(10.2 \mathrm{~cm} \times 10.2 \mathrm{~cm}$ x $40.8 \mathrm{~cm})$ thallium-doped sodium iodide [NaI(Tl)] detector, with a density of $3.67 \mathrm{~g} / \mathrm{cm}^{3}$ [Knoll 2002, page 234], the energy deposited in the crystal is found to be $74.5 \mathrm{MeV}$ :

$$
\begin{gathered}
\left(\frac{d E}{d x}\right)=\left(\frac{d E}{d \sigma}\right)(\rho)=\left(2 \frac{\mathrm{MeV}}{\left(\mathrm{g} / \mathrm{cm}^{2}\right)}\right)\left(3.67 \frac{\mathrm{g}}{\mathrm{cm}^{3}}\right)=7.34 \frac{\mathrm{MeV}}{\mathrm{cm}} \\
E_{\text {loss }}=\left(\frac{d E}{d x}\right)\left(d x_{\text {det ector }}\right)=\left(7.34 \frac{\mathrm{MeV}}{\mathrm{cm}}\right)(10.2 \mathrm{~cm})=74.5 \mathrm{MeV}
\end{gathered}
$$

Therefore, to detect the incident muons in a $\mathrm{NaI}(\mathrm{Tl})$ detector, the detector gain must be adjusted to extend the observed spectra to beyond $75 \mathrm{MeV}$. 


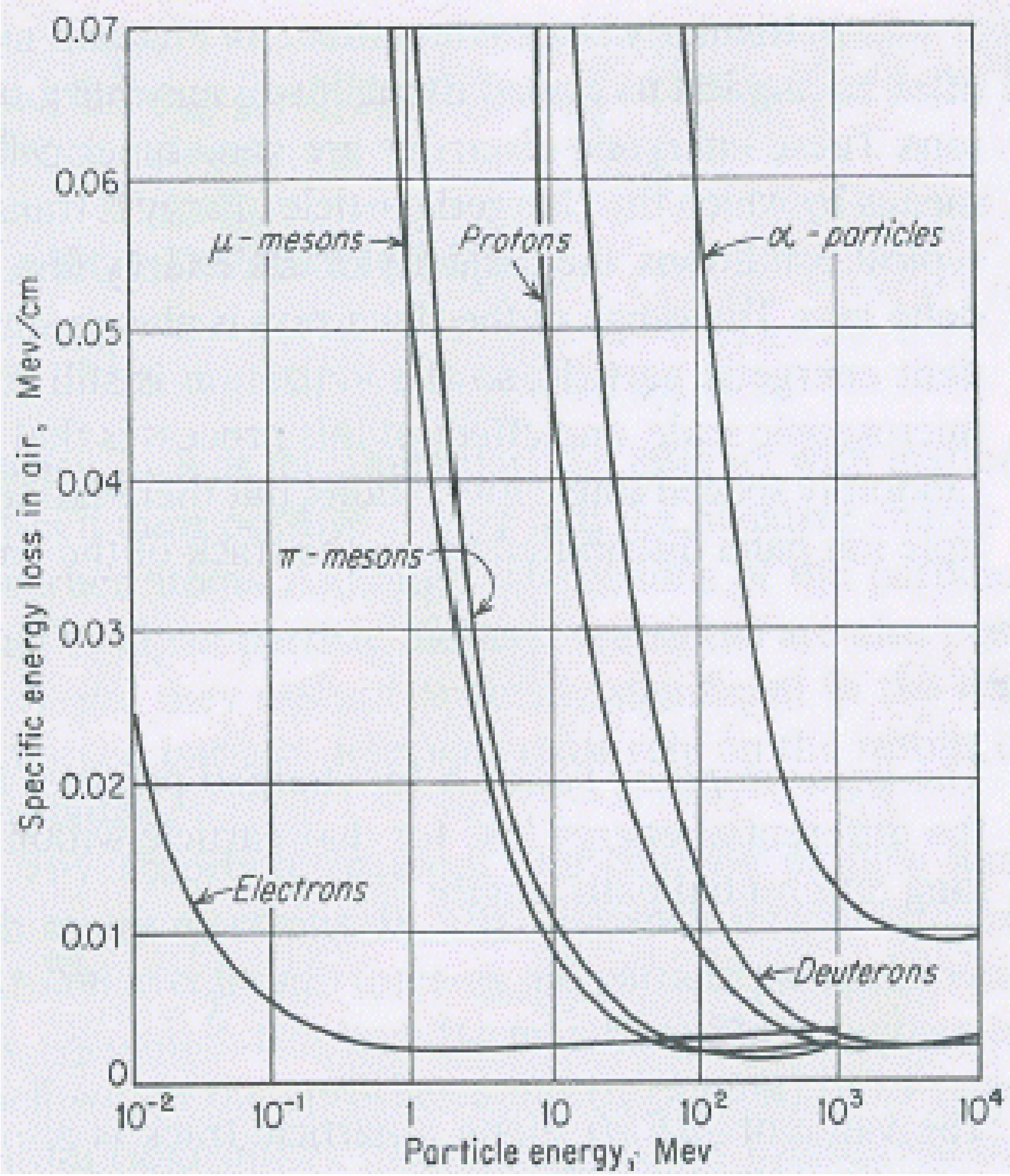

Figure 1. Variation of the specific energy loss in air versus energy of the charged particles shown. (From Beiser.2) [Knoll 2002, page 32] 


\section{Method}

To assess the attenuation in the underground facility, cosmic radiation measurements were taken at the surface to establish a comparative baseline with no terrestrial attenuation, and at several locations within Building 3425, the underground laboratory at a surface depth of 30' $(9.1 \mathrm{~m})$. Additional terrestrial shielding is provided by the earthen bunker on the surface (Figure $2 a$ and $2 b$ ), whose attenuation efficacy is being evaluated with these measurements.
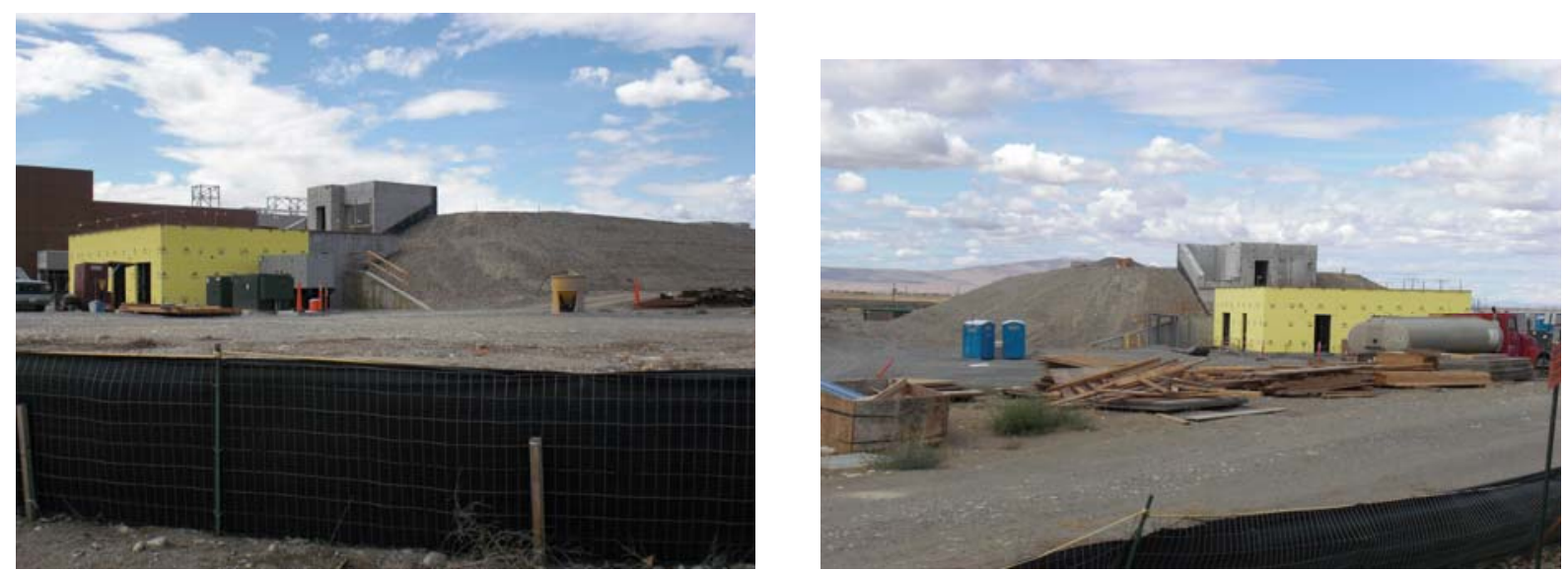

Figure 2. a) view of earthen bunker from NE; b) view of earthen bunker from SE

Data were collected utilizing a 4"x4"x16" NaI(Tl) detector (Scionix Holland, 3.5N-E2-X). Multi-channel analyzer emulation software (Ortec Maestro-32 v6.08) was used to collect and process the data. The detector is typically operated at a voltage of $\sim 535 \mathrm{~V}$, providing a full-scale upper energy threshold of $\sim 4 \mathrm{MeV}$. The energy spectrum is sequenced over 1024 channels, with a standard gain setting of 0.5 .

In an attempt to detect $\sim 75 \mathrm{MeV}$ cosmic rays, the gain and voltage were adjusted. The emulation software had a prescribed and unalterable lower gain limit of 0.4 , which prevented any meaningful increase in the high-energy sensitivity by this means. To increase the upper limit threshold, the operating voltage was progressively lowered to $375 \mathrm{~V}$ from the standard $535 \mathrm{~V}$ while tracking the location of the $1462 \mathrm{keV}^{40} \mathrm{~K}$ line in order. At an operating voltage of $375 \mathrm{~V}$, the $1462 \mathrm{keV}$ line had moved to channel $\sim 16$, corresponding to a full scale energy increase from $\sim 4 \mathrm{MeV}$ to $\sim 90 \mathrm{MeV}$.

$$
\left(\frac{1462 \mathrm{keV}}{\operatorname{chl~} 16}\right)=\left(\frac{E_{\text {full }} \mathrm{keV}}{\text { chl } 1024}\right) \Rightarrow E_{\text {full }}=\left(\frac{1462}{16}\right)(1024) \cong 90 \mathrm{MeV}
$$

This placed the $75 \mathrm{MeV}$ marker at channel $\sim 820$.

$$
\left(\frac{1462 \mathrm{keV}}{\operatorname{chl~} 16}\right)=\left(\frac{75000 \mathrm{keV}}{\operatorname{chl} \mathrm{x}}\right) \Rightarrow x=\left(\frac{75000}{1462}\right)(16)=\text { chl } 820
$$

Note that at this highly compressed scale the energy/channel ratio increased from $\sim 4 \mathrm{keV} / \mathrm{channel}$ (4MeV/1024 channels) to $\sim 90 \mathrm{keV} /$ channel (90MeV/1024 channels). 


\section{Results}

With this experimental setup, measurements were conducted at the surface with no terrestrial attenuation and at several sites at a surface depth of $30^{\prime}(9.1 \mathrm{~m})$ in the underground facility at 3425 . The earthen bunker provided additional shielding beyond this depth.

There was some concern regarding the performance of the $\mathrm{NaI}(\mathrm{Tl})$ crystal, which had previously been used at an outdoors site over a period of two weeks and was subject to diurnal environmental temperatures variations of $\sim 55^{\circ} \mathrm{F}$ to $\sim 106^{\circ} \mathrm{F}$. Several sealed sources with pronounced lines were used to check the performance of the instrument. In each case, identifiable peaks with no evidence of "double peaks" or decreased resolution, indicators of a cracked crystal, were observed. Figure 3 shows the resulting energy calibration with the detector set to an operating voltage of $535 \mathrm{~V}$ and a gain of 0.5 .

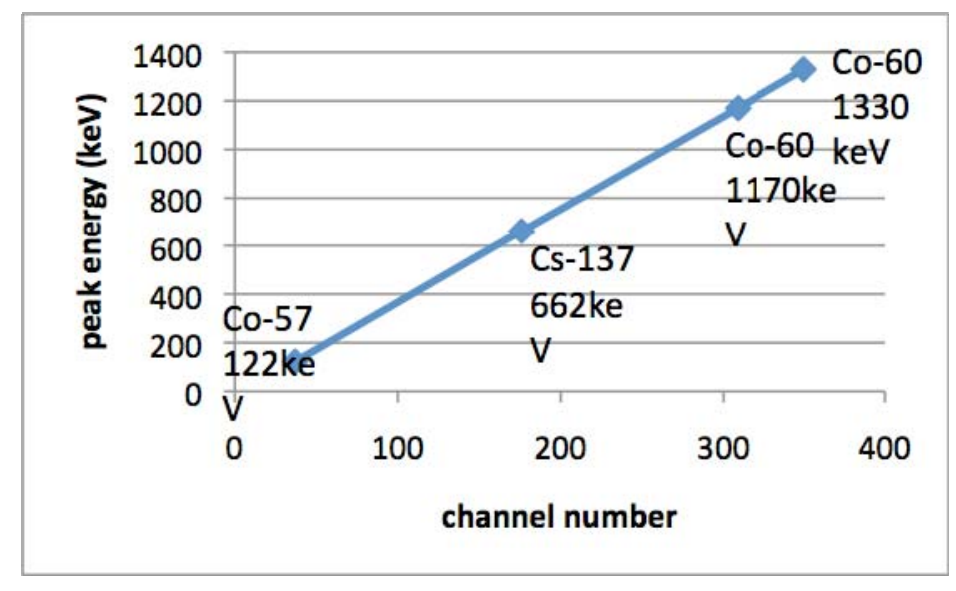

Figure 3. Energy calibration of $\mathrm{NaI}(\mathrm{Tl})$ detector at $535 \mathrm{~V}$

Surface measurements, each 10-minutes in duration at an operating voltage of $375 \mathrm{~V}$, were conducted at 3 locations in and around PNNL building 331G. The first measurement was performed on a tabletop inside 331G. The 1024 channels correspond to an energy range of 0 to $\sim 90 \mathrm{MeV}$. Results are shown below (Figures $4 \mathrm{a}$ and $4 \mathrm{~b}$ ). The cosmic "peak" appears at channel $\sim 720$.

The observed spectra consist of contributions from many factors. All of the natural radioactivity peaks are below $3 \mathrm{MeV}$ or channel $\sim 30$ with the ${ }^{40} \mathrm{~K}$ line is at channel $\sim 20$. This is consistent with the estimated full scale energy sensitivity of $\sim 90 \mathrm{MeV}$ [chl 1024/ 90 MeV $=\operatorname{chl} \mathrm{x} / 3 \mathrm{MeV}]$. The muons deposit energy as minimally ionizing particles, producing the broad peak centered around channel $\sim 720$ [chl 1024/ 90 MeV $=\mathrm{chl} \mathrm{x} / \sim 70 \mathrm{MeV}]$ in Figure $4 \mathrm{~b}$. The rest of the counts below this muon feature arise from other cosmic sources including protons, neutrons, and gamma rays. 

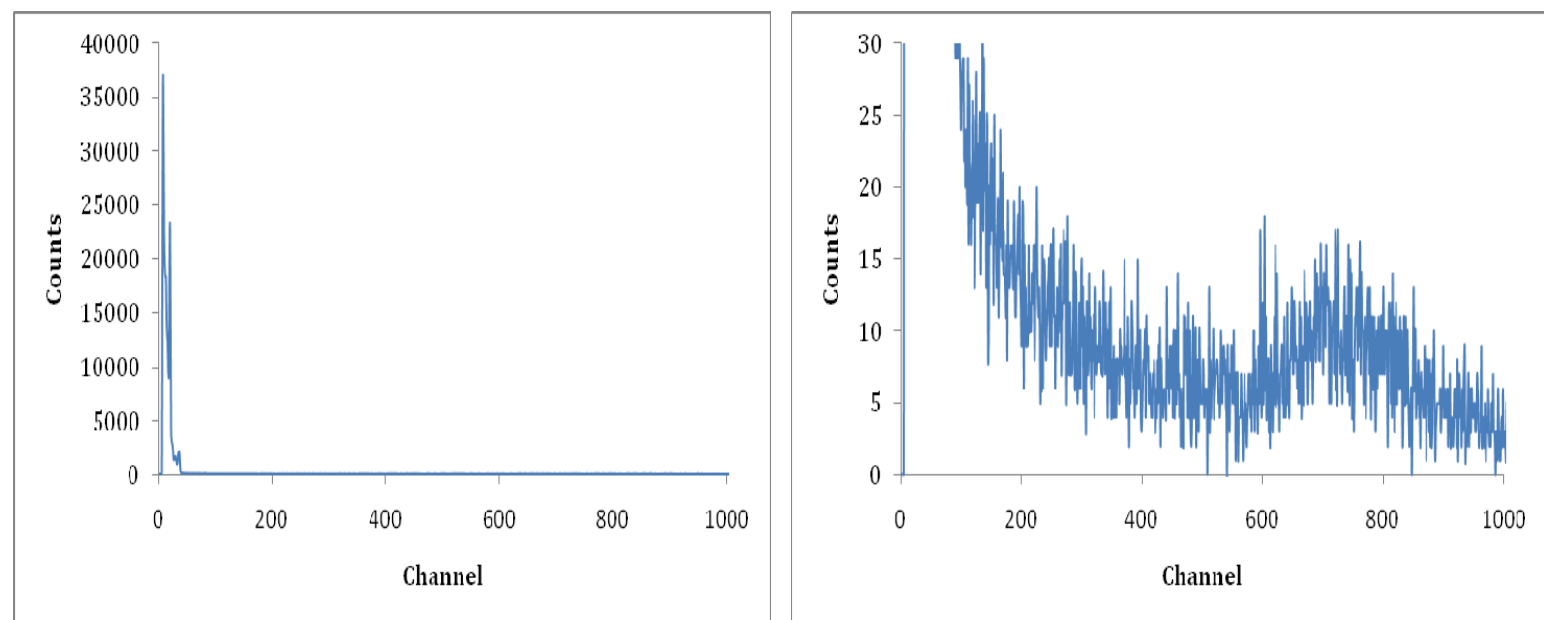

a) Indoor spectrum at $375 \mathrm{~V}$

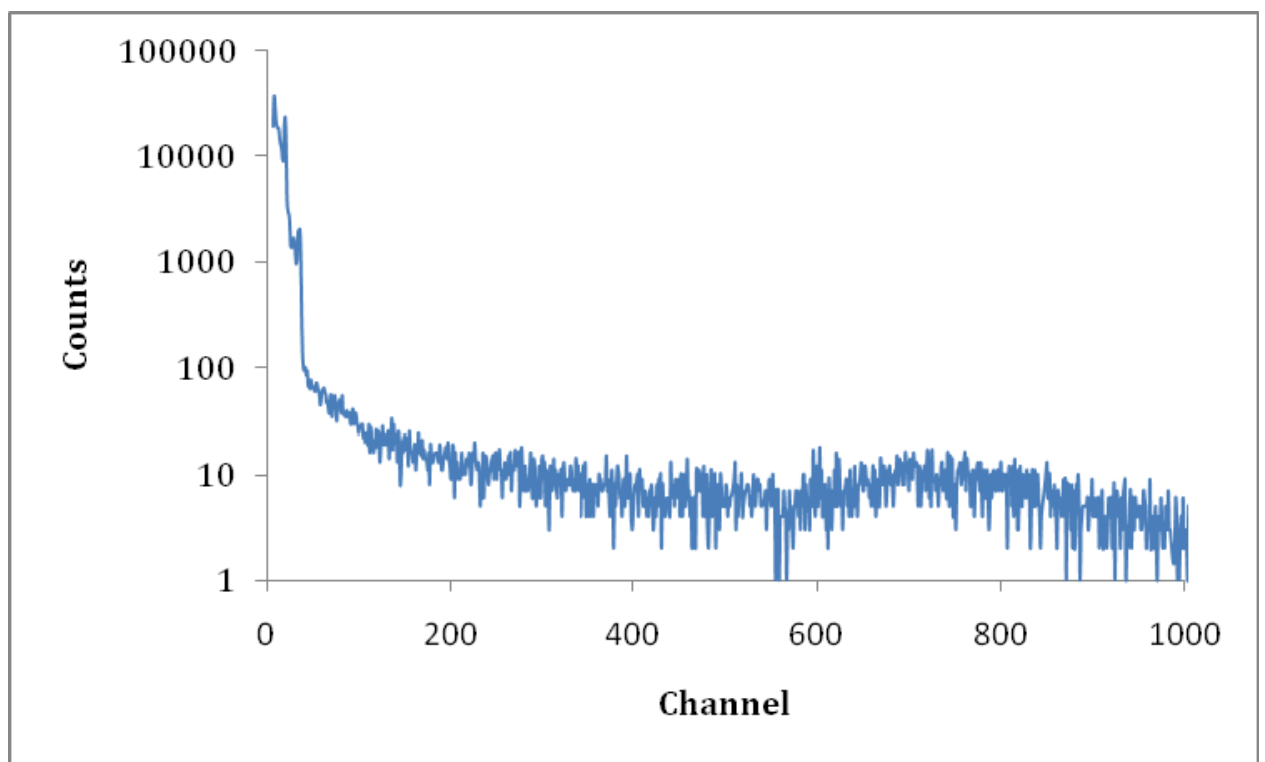

b) Logrithmic scale of indoor spectrum at $375 \mathrm{~V}$

Figure 4. Indoor spectra

Since not all interacting cosmic rays deposit the average minimally ionizing energy in the crystal, the peak is broad. Since the detector, when set sideways, presents an area of $4^{\prime \prime} \times 16^{\prime \prime}(10.2 \mathrm{~cm} \times 40.6 \mathrm{~cm})$, or $0.0413 \mathrm{~m}^{2}$, to the sky, a 10 minute collection should yield $\sim 200$ muons, assuming each is detected.

$$
\left(\frac{170 \text { muons }}{m^{2} \cdot \sec }\right)\left(0.0413 \mathrm{~m}^{2}\right)(600 \mathrm{sec}) \cong 4200 \text { muons }
$$

Table 1 shows integrated counts for several channel ranges shown in Figures $4 \mathrm{a}$ and $4 \mathrm{~b}$. Red arrows indicate the lower bounds. Energy ranges are approximations. The $3.6-90 \mathrm{MeV}$ integrated sum is a factor of $\sim 4.4$ times greater than the theoretical 4200 muons found above presumably from the detection 
of non-muon cosmic radiation. Note that integrating over the energy range $\sim 40 \mathrm{MeV}-90 \mathrm{MeV}$ (channels 450-1023) yields approximately the expected muon flux.

Table 1. Integrated counts for several energy limits for data from inside 331G

\begin{tabular}{|c|c|c|}
\hline Channel range & $\sim$ Energy $(\mathrm{MeV})$ & Sum, counts \\
\hline $40-1023$ & $3.6-90$ & 18569 \\
\hline $92-1023$ & $8.3-90$ & 8430 \\
\hline $400-1023$ & $36-90$ & 4168 \\
\hline $450-1023$ & $40-90$ & 3854 \\
\hline $500-1023$ & $45-90$ & 3518 \\
\hline $557-1023$ & $50-90$ & 3151 \\
\hline
\end{tabular}
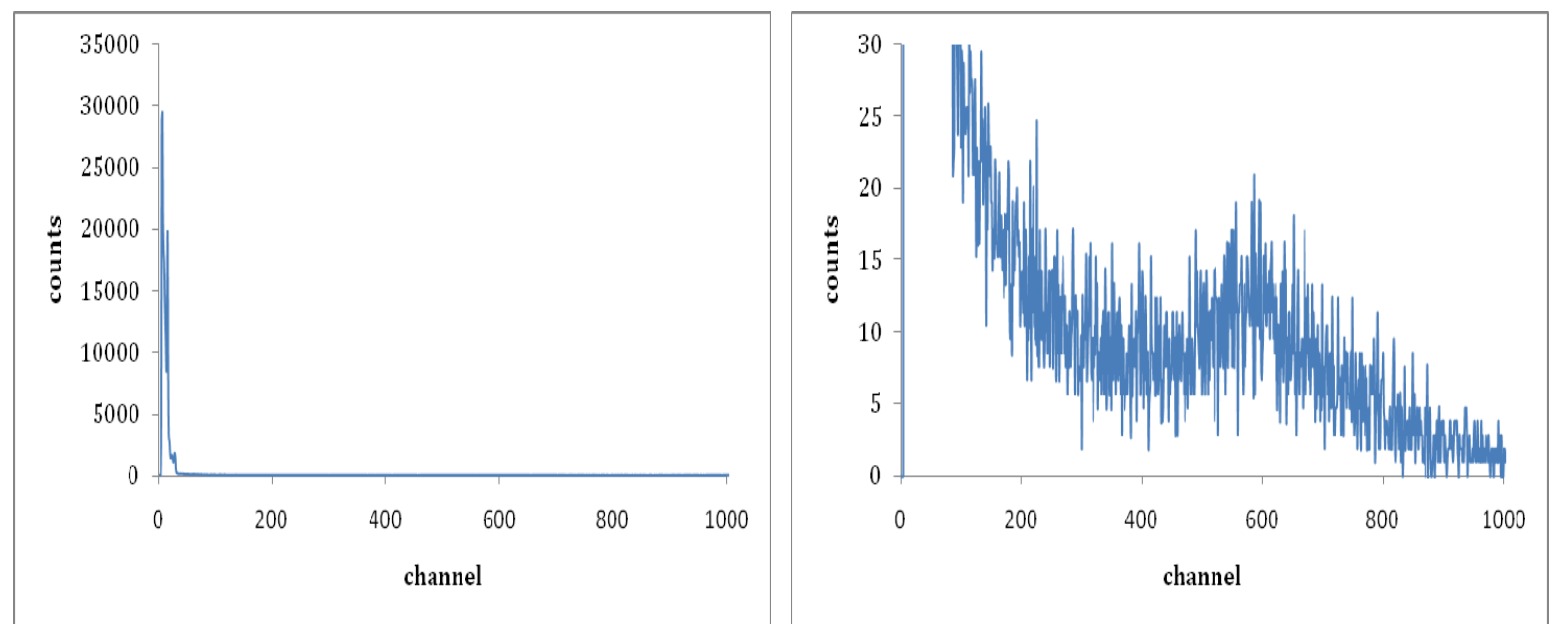

Figure 5. Spectra outdoors at portals (375V). Right hand plot is an expansion of the ordinate.

The second measurement was performed on a plastic picnic table located by the SAIC POV portals $\sim 100$ $\mathrm{ft}(30 \mathrm{~m})$ southwest of $331 \mathrm{G}$. Results are shown in Figure 5. The cosmic "peak" appears at channel $\sim 600$.

Table 2 shows integrated counts for several channel ranges shown in Figure 5. Red arrows indicate the lower bounds. Energy ranges are approximations. The $3.6-90 \mathrm{MeV}$ integrated sum is a factor of $\sim 3.1$ times greater than the theoretical 4200 muons found above, while the range $\sim 40 \mathrm{MeV}-90 \mathrm{MeV}$ (channels 450-1023) again approximates the expected muon fluence.

Table 2. Integrated counts for several energy limits outside 331G

\begin{tabular}{|l|c|l|}
\hline \multicolumn{1}{|c|}{ Channel range } & $\sim$ Energy $(\mathrm{MeV})$ & Sum (counts) \\
\hline $40-1023$ & $3.6-90$ & 13191 \\
\hline $92-1023$ & $8.3-90$ & 8952 \\
\hline $400-1023$ & $36-90$ & 4312 \\
\hline $450-1023$ & $40-90$ & 3862 \\
\hline
\end{tabular}


The third measurement was performed on the ground $\sim 40 \mathrm{ft}(12 \mathrm{~m})$ south of $331 \mathrm{G}$, under the chained perimeter dividing the $331 \mathrm{G}$ racetrack from the adjacent field. Results are shown in Figure 6 . The cosmic "peak" appears at channel $\sim 700$. Table 3 shows integrated counts for several channel ranges. The $3.6-90 \mathrm{MeV}$ integrated sum is a factor of $\sim 4.8$ times greater than the theoretical 4200 muons found above, while counts over the energy range $\sim 40 \mathrm{MeV}-90 \mathrm{MeV}$ (channels 450-1023) produce the theoretical muon flux.
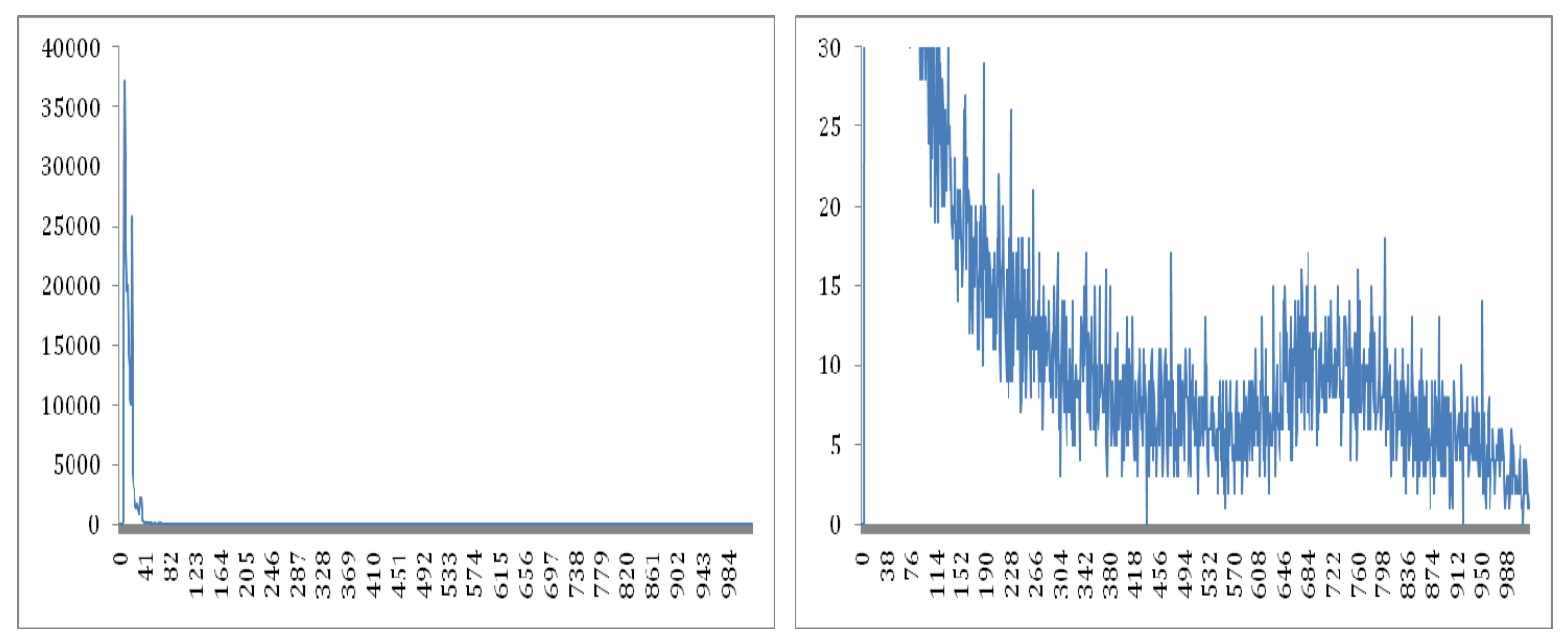

Figure 6. Outdoor spactra on ground (375V). Right hand plot is an expansion of the ordinate.

Table 3. Integrated counts for several energy limits on the ground outside 331G

\begin{tabular}{|l|c|l|}
\hline \multicolumn{1}{|c|}{ Channel range } & Energy $(\mathrm{MeV})$ & Sum (counts) \\
\hline $40-1023$ & $3.6-90$ & 19998 \\
\hline $92-1023$ & $8.3-90$ & 9017 \\
\hline $400-1023$ & $36-90$ & 4329 \\
\hline $450-1023$ & $40-90$ & 3669 \\
\hline $536-1023$ & $50-90$ & 3361 \\
\hline
\end{tabular}

The underground measurements were made at night and over the course of a weekend to avoid construction crews and other personnel. Thus, the measurement times varied from 7 to 33 hours; the results were all scaled to 10 minutes. Measurements were made at four locations with an operating voltage of $375 \mathrm{~V}$ corresponding to an estimated $\sim 90 \mathrm{MeV}$ full scale sensitivity.

The first underground location was on the ground in the shaft. The shaft is a rectangular vertical opening to the sky that is about 15 feet by 20 feet $(4.6 \mathrm{~m} \times 6.1 \mathrm{~m})$. The muon flux observed at this location should be much larger than other sites in the underground laboratory. The results from this measurement, time corrected, are shown in Figures $7 \mathrm{a}$ and $7 \mathrm{~b}$. The cosmic "peak" appears around channel 700. Table 4 shows the integrated counts for the channel ranges chosen. 

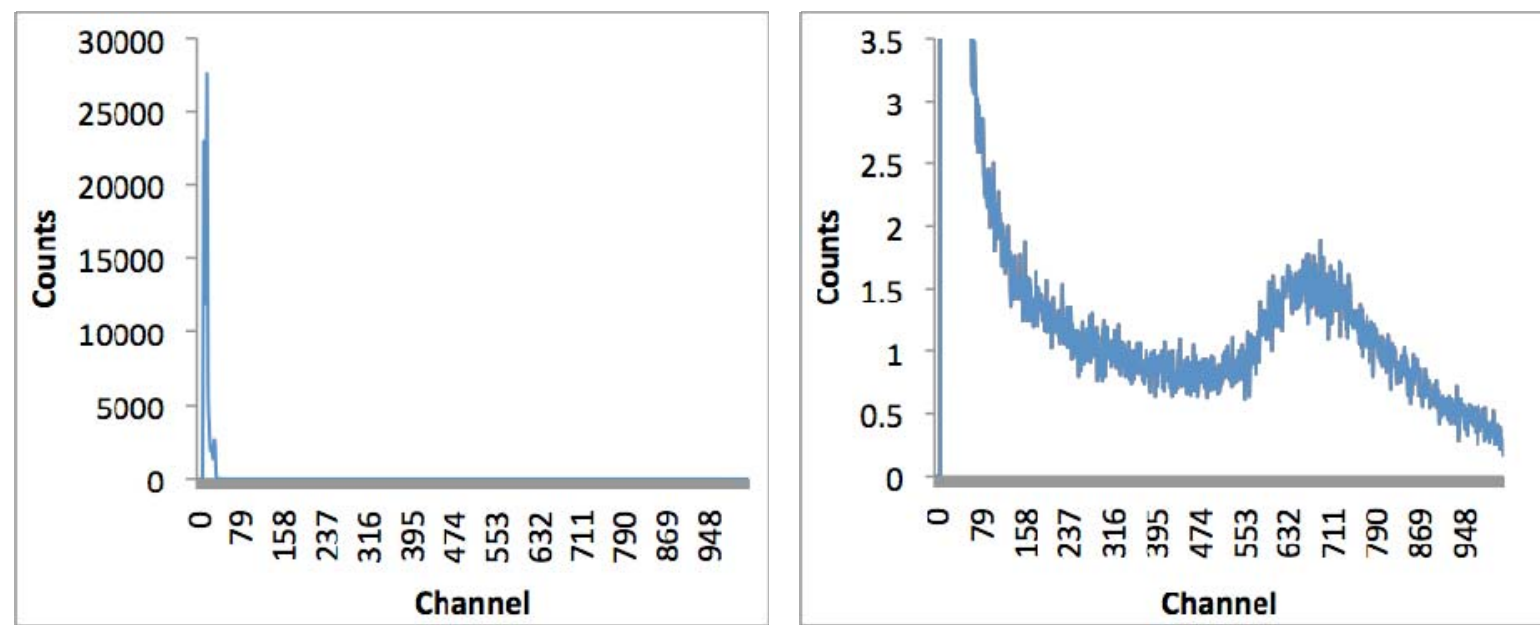

Figure 7. a) Underground spectrum in shaft (375 V); b) Magnified underground spectrum in shaft (375 V)

Table 4. Integrated counts for several energy limits in the shaft at the underground laboratory.

\begin{tabular}{|l|c|l|}
\hline \multicolumn{1}{|c|}{ Channel range } & $\sim$ Energy $(\mathrm{MeV})$ & Sum (counts) \\
\hline $40-1023$ & $3.6-90$ & 2659 \\
\hline $92-1023$ & $8.3-90$ & 1679 \\
\hline $450-1023$ & $40-90$ & 989 \\
\hline $572-1023$ & $51-90$ & 851 \\
\hline
\end{tabular}

The second underground location was near the West wall. Measurements were acquired over the course of 14 hours and time corrected to get the number of counts recorded in 10 minutes. The results from this measurement are shown in Figures 8a and 8b. The cosmic "peak" appears around channel 770. Table 5 shows the integrated counts for the channel ranges selected based on the features of the spectra in Figures $8 \mathrm{a}$ and $8 \mathrm{~b}$.
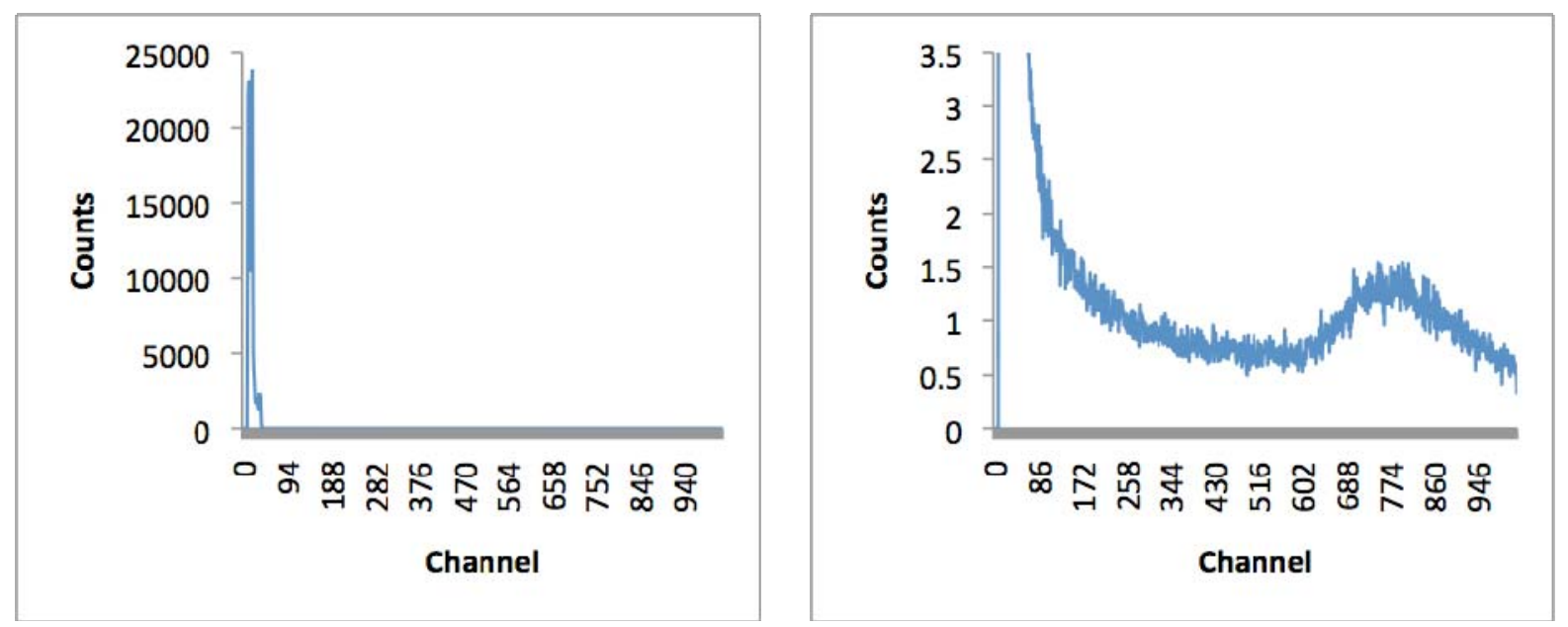

Figure 8. a) Underground spectrum near west wall (375 V); b) Magnified spectrum near west wall (375 V) 
Table 5. Integrated counts for several energy limits made near the west wall.

\begin{tabular}{|l|c|l|}
\hline \multicolumn{1}{|c|}{ Channel range } & $\sim$ Energy $(\mathrm{MeV})$ & Sum (counts) \\
\hline $40-1023$ & $3.6-90$ & 1231 \\
\hline $92-1023$ & $8.3-90$ & 976 \\
\hline $450-1023$ & $40-90$ & 549 \\
\hline $498-1023$ & $45-90$ & 510 \\
\hline
\end{tabular}

The third underground location was made with the detector located in the middle of the room. Data were collected over 16 hours. The results from this location, time corrected, are shown in Figures $9 \mathrm{a}$ and $9 \mathrm{~b}$. The cosmic "peak" occurs around channel 745. The integrated counts for the channel ranges selected shown in Table 6.
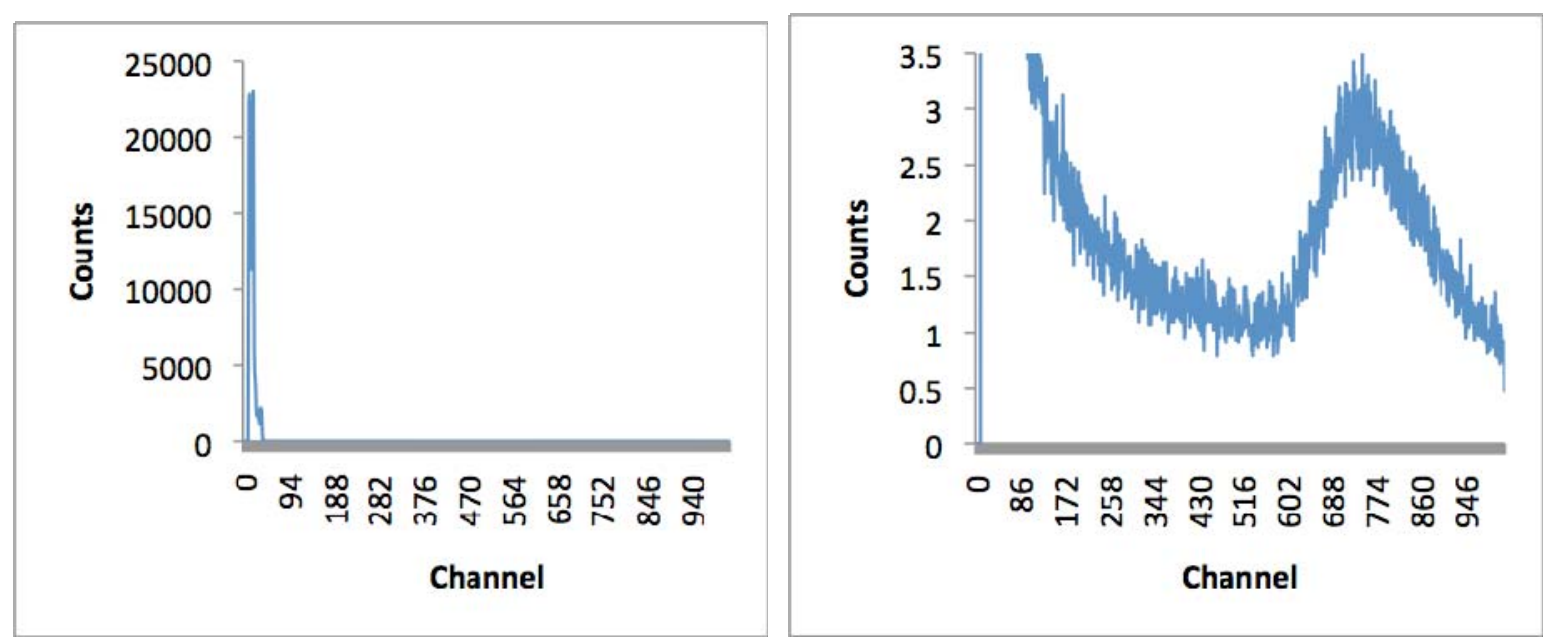

Figure 9. a) Underground spectrum center of room (375 V); b) Magnified spectrum center of room (375 V)

Table 6. Integrated counts for several energy limits in the middle of the underground laboratory.

\begin{tabular}{|l|c|l|}
\hline \multicolumn{1}{|c|}{ Channel range } & $\sim$ Energy $(\mathrm{MeV})$ & Sum (counts) \\
\hline $40-1023$ & $3.6-90$ & 1521 \\
\hline $92-1023$ & $8.3-90$ & 921 \\
\hline $450-1023$ & $40-90$ & 523 \\
\hline $616-1023$ & $55-90$ & 407 \\
\hline
\end{tabular}

The final underground location was at the East end of the room. Data in this trial were collected over 33 hours. Figures $10 \mathrm{a}$ and $10 \mathrm{~b}$ show the results from this location corrected for time and with the same axis scales as the other underground measurements. The cosmic "peak" occurs around channel 775. Table 7 shows the integrated counts for the channel ranges based on the features of the spectra in Figures 10a and $10 \mathrm{~b}$. 

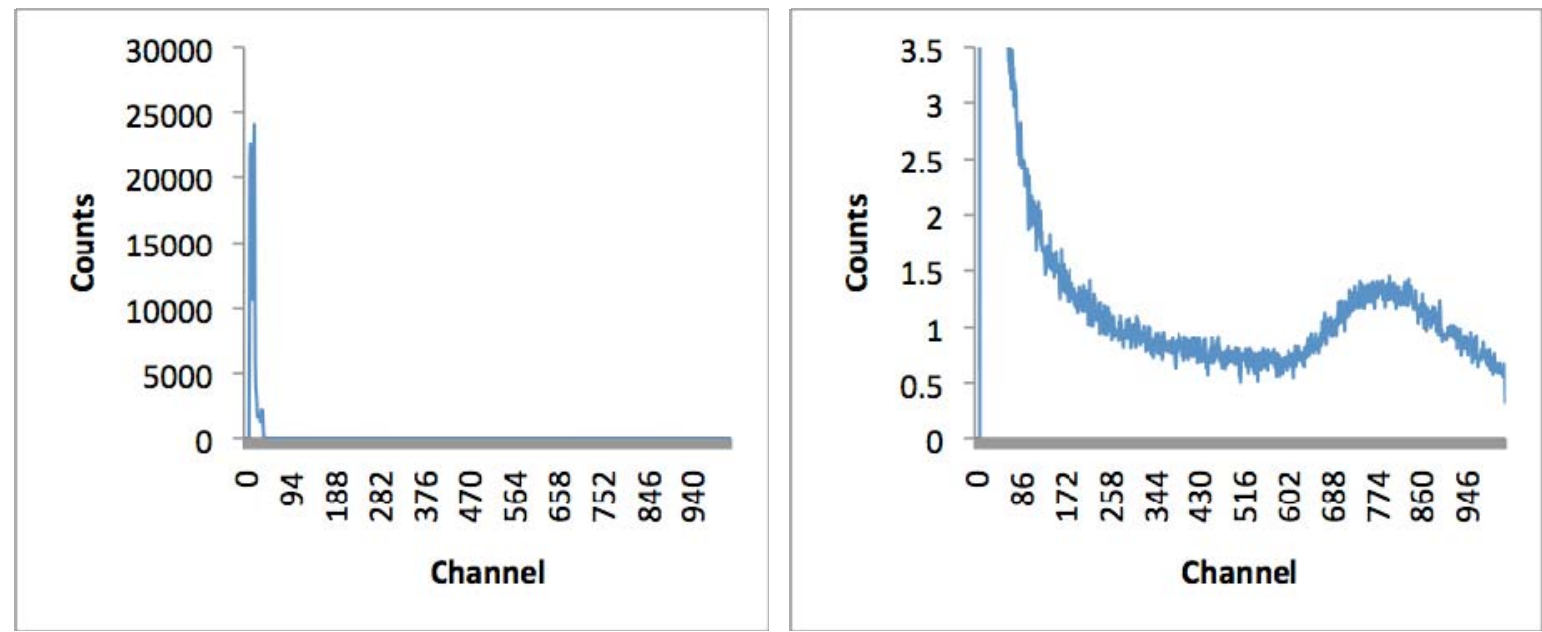

Figure 10. a) Underground spectrum near east wall (375 V); b) Magnified spectrum near east wall (375 V)

Table 7. Integrated counts for several energy limits at the east end of the underground laboratory.

\begin{tabular}{|l|c|l|}
\hline \multicolumn{1}{|c|}{ Channel range } & $\sim$ Energy $(\mathrm{MeV})$ & Sum (counts) \\
\hline $40-1023$ & $3.6-90$ & 1774 \\
\hline $92-1023$ & $8.3-90$ & 945 \\
\hline $450-1023$ & $40-90$ & 532 \\
\hline $616-1023$ & $55-90$ & 415 \\
\hline
\end{tabular}




\section{Discussion}

Table 8 summarizes the data obtained at each location for the energy region spanning $\sim 40-90 \mathrm{MeV}$ (Channels 450-1023). This range encompasses the muon "peak" for all locations. It can be seen that this muon peak appears to move. Some of this motion can be attributed to differences in the spectrum caused by shielding. The spectrum underground is 'harder,' as indicated by the average channel location of the muon peaks, $\sim 763$, measured at the East, middle and West, compared to the above ground values that ranged from $\sim 600-720$ (average of 673). Shifts may also occur because of temperature changes.

As indicated previously, the expected muon flux at the surface is $\sim 4200$ counts in 10 minutes. The energy range chosen ( 40-90 MeV) gives an average gross count value of 3795 counts above ground. The average value of the three locations underground is 532 gross counts. The value in the shaft is seen to be intermediate between the underground and above ground values, as expected. The ratio of these average gross counts below ground to above ground is $\sim 14 \%$. A similar comparison can be performed for net counts, where a flat background is subtracted. These net counts produce a ratio of $\sim 16 \%$, so there is little difference between the two approaches.

Table 8. Summary of counts for each location for energies of $\sim 40-90 \mathrm{MeV}$ (Channels 450-1023).

\begin{tabular}{|l|c|c|c|}
\hline \multicolumn{1}{|c|}{ Location } & Peak Centroid & Gross Sum & Net Sum \\
\hline 331G Inside & 720 & 3854 & 1527 \\
\hline 331G Outside & 600 & 3862 & 1535 \\
\hline 331G on Ground & 700 & 3669 & 1641 \\
\hline Average Above Ground & $\mathbf{6 7 3}$ & $\mathbf{3 7 9 5}$ & $\mathbf{1 5 6 8}$ \\
\hline Shaft & 700 & 989 & 416 \\
\hline East & 775 & 532 & 262 \\
\hline Middle & 745 & 523 & 236 \\
\hline West & 770 & 549 & 246 \\
\hline Average Below Ground & $\mathbf{7 6 3}$ & $\mathbf{5 3 2}$ & $\mathbf{2 4 8}$ \\
\hline
\end{tabular}

A number of assumptions need to be made, if only a simple analysis is to be performed. First, we will assume the gross counts found in the region of interest are from muons, which tends to overestimate the flux at the surface. Second, we ignore any potential surface contributions originating from noncollimated sources that result from variations in the azimuthal angle when comparing the above ground and underground values. This overestimates the surface counts that are within the small angular distribution that survive to the underground location relative to the surface. Both of these factors tend to overestimate the depth of the facility. We also assume a simple model is valid for shallow depths, though it was developed it was developed for measurements at deeper locations. In order to use these data to determine an effective depth for the underground facility, a formula is needed for intensity as a function of depth. We use the equation given by Barbouti and Rastin [Grieder 2001, p 486] for intensity as a function of depth:

$$
I=\frac{K e^{-\beta X}}{\left(X^{\alpha}+a\right)(X+H)}
$$

where $\mathrm{K}=270.7 \mathrm{hg} / \mathrm{cm}^{2}, \mathrm{a}=75, \mathrm{H}=200 \mathrm{hg} / \mathrm{cm}^{2}, \alpha=1.68, \beta=5.5 \times 10^{-4} \mathrm{~cm}^{2} / \mathrm{hg}$, and $\mathrm{X}$ is in units of $\mathrm{hg} / \mathrm{cm}^{2}$ (which is approximately the same as meters water equivalent (mwe)). The resulting intensity (I) is in units 
of $\mathrm{cm}^{-1} \mathrm{~s}^{-1} \mathrm{sr}^{-1}$. The depth is measured from the top of the atmosphere and sea level is at a depth of $\sim 1000$ $\mathrm{g} / \mathrm{cm}^{2}\left(10 \mathrm{hg} / \mathrm{cm}^{2}\right)$.

Table 9 provides results from this formula of the intensity as a function of depth (in mwe) expressed as the ratio of the result relative to the result at $10 \mathrm{hg} / \mathrm{cm}^{2}(\sim$ sea level).

Table 9. Muon intensity as a function of depth

\begin{tabular}{|r|c|}
\hline \multicolumn{1}{|c|}{ X (mwe) } & Ratio to Sea Level (10 mwe) \\
\hline 0 & 1.730 \\
\hline 5 & 1.403 \\
\hline 10 & 1.000 \\
\hline 15 & 0.706 \\
\hline 20 & 0.511 \\
\hline 25 & 0.381 \\
\hline 30 & 0.293 \\
\hline 35 & 0.232 \\
\hline 40 & 0.187 \\
\hline 45 & $\mathbf{0 . 1 5 3}$ \\
\hline 50 & 0.128 \\
\hline 55 & 0.108 \\
\hline 60 & 0.092 \\
\hline 65 & 0.080 \\
\hline 70 & 0.069 \\
\hline
\end{tabular}

With these results and the assumptions stated, the equivalent depth of the facility is $\sim 45$ mwe from the top of the atmosphere (representing a "depth" of 10 mwe), or $\sim 35$ mwe shielding from the ground (which has $\sim 15 \%$ of the surface flux compared to $14-16 \%$ from the experimental results). 


\section{Conclusions}

The result of the measurement indicates that the maximum depth of the underground facility (Building 3425 ) is $~ 35$ meters water equivalent from the surface. The specification for the construction of this facility is $30 \mathrm{~m}$ water equivalent. The measured value is a maximum, since the measured surface flux has contributions to the spectrum from sources other than muons. This approach results in increased counts at the surface and, thus, overestimates the effect of the depth, since most surface contributions, other than muons, are easily stopped within a short penetration of the soil.

The actual effective depth of the laboratory could be less than the value found here. A more controlled measurement using a detector collimated upward should be used to eliminate a contribution from a large solid angle at the surface. In addition, a surface measurement should be made using a top shield of welldefined effect, such as a concrete block, that is thick enough to eliminate the contributions from cosmic ray charged particles and neutrons. This would then allow a better comparison to the rate observed at the underground location. In addition, a more current theoretical model may be available for muon attenuation at shallow depths, since the model used was developed for deeper applications. The present results thus give an approximate value for the depth and were motivated by rapidly obtaining a first measurement. Having made these measurements will provide the foundation for making a more accurate future measurement. 


\section{References}

Keller PE, and RT Kouzes. 2009. "Influence of Extraterrestrial Radiation on Radiation Portal Monitors", IEEE Transactions on Nuclear Science 56 (3). pp 1575-1583.

Knoll GF. 2002. Radiation Detection and Measurement $3^{\text {rd }}$ Ed. John Wiley and Sons, New York. Grieder PKF. 2001. Cosmic Rays at Earth, Elsevier, Amsterdam. 